\title{
Prediksi Peningkatan Sedimentasi Dengan Metode Angkutan Sedimen (Studi Kasus Sedimentasi Di Waduk Mrica)
}

\author{
Teguh Marhendi ${ }^{1}$, Dewi laras Sulastri Ningsih ${ }^{2}$ \\ ${ }^{1,2}$ Program Studi Teknik Sipil, Universitas Muhammadiyah Purwokerto
}

Informasi Makalah

Dikirim, 24 Juli 2018

Direvisi, 08 Oktober 2018

Diterima, 09 Oktober , 2018

\section{Kata Kunci:}

Sedimentasi

Angkutan sedimen

Metode Mayer Petter Muller

Waduk Mrica

\section{Keyword:}

Sedimentation

Sediment transport

Mayer Petter Muller method

Mrica Reservoir

\begin{abstract}
INTISARI
Permasalahan sedimentasi di Waduk Mrica berdampak pada pengurangan kapasitas maupun umur fungsi waduk. Sedimentasi terjadi karena proses erosi di hulu daerah aliran sungai di hulu Waduk Mrica dan tertampung atau mengendap pada waduk. Penelitian ini bertujuan untuk mengetahui peningkatan sedimentasi di Waduk Mrica menggunakan metode angkutan sedimen. Analisis dilakukan dengan menghitung angkutan sedimen yang melayang dan mengendap menggunakan metode Mayer Petter Mullermelalui pendekatan empirik. Berdasarkan analisis tersebut, selanjutnya dilakukan prediksi 10 tahun terakhir (2005-2014) dan menghitung prediksi 10 tahun mendatang (2015-2024). Analisis Statistika dihitung menggunakan metode Gumbel dan Log Person Tipe III. Hasil penelitian menunjukkan bahwa debit sedimen yang masuk waduk sejak tahun 2005-2014 cenderung berfluktuatif dengan rerata $0,005 \mathrm{~T} /$ hari tiap tahun. Sedangkan dari analisis prediksi tahun 2015-2024, diprediksi terus mengalami peningkatan dengan rerata peningkatan $11,11 \%$ tiap tahun.
\end{abstract}

\begin{abstract}
Sedimentation problems in Mrica Reservoir have impact on capacity reduction and function of reservoir. Sedimentation occurs due to the erosion process in the upper watershed upstream of the Mrica Reservoir and accommodated or settles in reservoir. This study aims to determine the increase of sedimentation in Mrica Reservoir using sediment transport method. The analysis was performed by calculating the drifting and sedimental sediment transport using the Mayer Petter Mullerm method through the empirical approach. Based on the analysis, the next 10 years (2005-2014) predicted and calculated the prediction of the next 10 years (2015-2024). Statistical analysis is calculated using the Gumbel method and Type III Log Person. The results showed that the sediment discharge entering the reservoir from 2005-2014 tended to fluctuate with a mean of $0.005 \mathrm{~T} /$ day per year. While from the prediction analysis in $2015-2024$, it is predicted to continue to increase with an average increase of $11.11 \%$ per year.
\end{abstract}

\section{Korespondensi Penulis:}

Penulis Ke-1

Program Studi Teknik Sipil

Universitas Muhammadiyah Purwokerto

Jl Raya Dukuhwaluh Purwokerto

Email: tmarhendi@gmail.com, teguhmarhendi@ump.ac.id

\section{PENDAHULUAN}

Waduk-waduk yang ada di Indonesia tidak terlepas dengan adanya proses sedimentasi yang terangkut dengan muatan melayang (suspended load) dan dasar (bed load). Hal ini menjadikan permasalahan meningkatnya produksi sedimen dan berdampak pada pengurangan kapasitas maupun umur fungsi waduk[1]. Beberapa waduk di Indonesia umumnya mengalami masalah operasional tersebut, dibuktikan dengan 
meningkatnya sedimentasi sepanjang tahun [1],[2]. Sebagai salah satu contohnya waduk Mrica yang berada di Banjarnegara. Waduk Mrica ini merupakan waduk yang sangat potensial untuk menampung air dengan kapasitas sebanyak 148,287 juta m3. Sedimentasi pada waduk Mrica terjadi akibat erosi lahan atau tanah yang terbawa, ataupun tergerus oleh sungai-sungai yang mengarah pada hulu waduk Mrica pada Daerah Aliran Sungai (DAS) [3],[4]. Berdasarkan laporan PT. Indonesia Power UPB Mrica, volume sedimentasi pada tahun 2010 sudah mencapai 60 \%, pada tahun 2014 mencapai 71\%, dan pada tahun 2015 sedimen waduk Mrica telah memasuki fase kritis karena telah memenuhi sekitar 71,66\% volume waduk. Sehingga menuntut untuk segera dilakukan penanganan untuk mengatasi permasalahan sedimentasi waduk ini.

Peningkatan sedimentasi di Waduk Mrica berlangsung sepanjang tahun. Sejak beroperasi tahun 1989 sampai 2017 kumulatif sedimentasi yang masuk ke waduk telah mencapai 114 juta m3 [5], sebagaimana pada Gambar 1. Peningkatan sedimentasi sebagaimana Gambar 1, dilakukan berdasarkan aktifitas echosounding PT Uni Indonesia Power UBP Waduk Mrica sampai tahun 2017. Peninjauan peningkatan debit sedimen dalam analisis dapat juga dilakukan berdasarkan persamaan empiris seperti penggunaan metode angkutan sedimen. Pada kajian ini, analisis peningkatan sedimentasi dilakukan berdasarkan rumus empiris angkutan sedimen metode Mayer Petter Muller [6]. Sedang prediksi peningkatan sedimen 10 tahun berikutnya dilakukan menggunakan metode statistika.

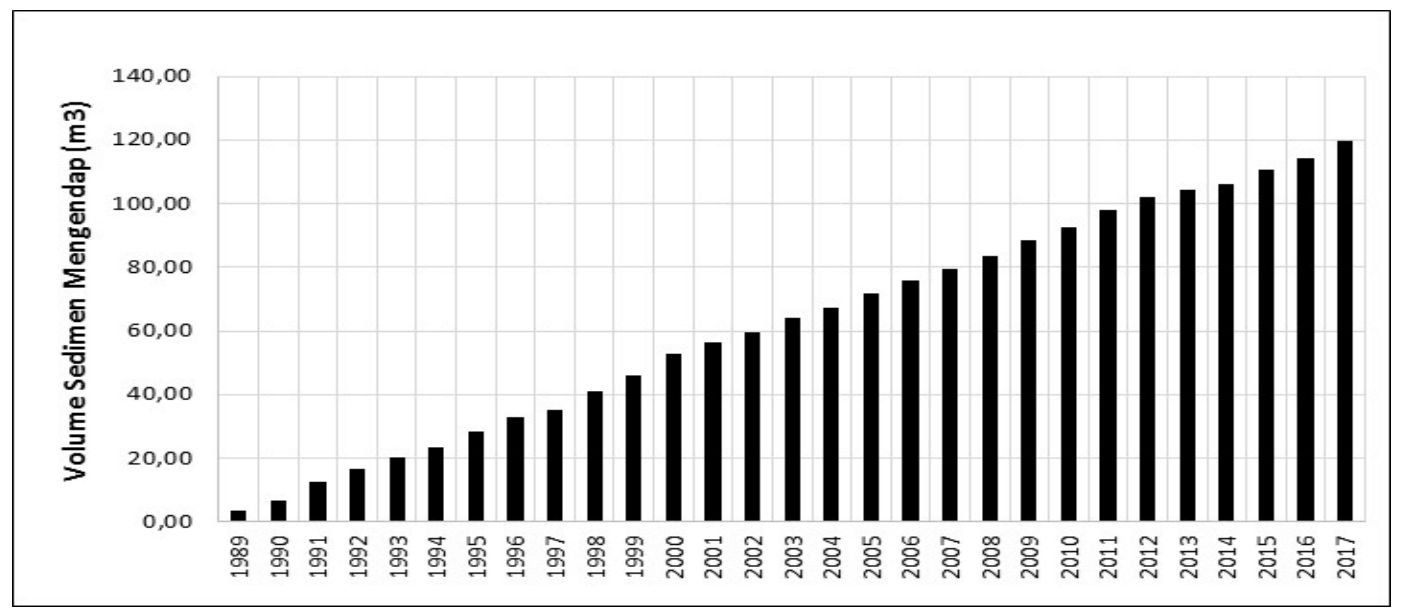

Gambar 1. Kumulatif Sedimen yang masuk ke Waduk Mrica Sumber: T. Marhendi, 2018

Beberapa kajian terkait penelitian sedimentasi waduk banyak dilakukan beberapa peneliti sebelumnya. Diantaranya yaitu penelitian terkait Analisis Volume Sedimen Waduk Wonogiri di Muara Sungai Keduang [7]. Penelitian ini bertujuan untuk mengetahui jumlah sedimen yang terbawa masuk ke Waduk Wonogiri oleh Sungai Keduang. Analisis jumlah volume sedimen menggunakan metode Meyer Peter dan Muller. Hasil analisis perhitungan sedimen Waduk Wonogiri di Muara Sungai Keduang dari tahun 2006 sampai 2012 adalah 6.184.308,84 m3/tahun. Perhitungan sedimen berhubungan dengan debit di muara sungai Keduang, dalam analisis peroleh persamaan rating curve : $\mathrm{Y}=0,0146859801 . \mathrm{X}^{0,315965501}$

Penelitian lain terkait Analisis Angkutan Sedimen Dasar Sungai Progo Dengan Metode Empiris (Meyer-Peter \& Muller, Einstein Dan Frijlink) [8]. Penelitian ini bertujuan untuk mengetahui hasil analisis pada penelitian angkutan sedimen di Sungai Progo. Dari hasil analisis kapasitas transport sedimen dasar (bedload) mengunakan metode empiris di Sungai Progo, pada lokasi penelitian diketahui sebagai berikut:

1. Hasil analisis kapasitas transport sedimen dasar (bedload) Metode MeyerPeter and Muller sebagai berikut: Pias Jembatan Bantar pada pengukuran kapasitas angkutan sedimen sebesar 412,530 m3/day, sedangkan Pias Intake Sapon pada pengukuran kapasitas angkutan sedimen sebesar 634,138 m3 /day.

2. Hasil analisis kapasitas transport sedimen dasar (bedload) Metode Einstein sebagai berikut: Pias Jembatan Bantar pada pengukuran kapasitas angkutan sedimen sebesar 101,959 m3/day, sedangkan Pias Intake Sapon pada pengukuran kapasitas angkutan sedimen sebesar 227,864 m3/day.

3. Hasil analisis kapasitas transport sedimen dasar (bedload) Metode Frijlink sebagai berikut : Pias Jembatan Bantar pada pengukuran kapasitas angkutan sedimen sebesar 237,512 m3/day, sedangkan Pias Intake Sapon pada pengukuran kapasitas angkutan sedimen sebesar 362,138 m3/day. 
Sementara itu, dalam [9], dilakukan penelitian terkait Analisis Laju Angkutan Sedimen bagi Perhitungan Kantong Lumpur Pada D.I. Perkotaan Kabupaten Batubara. Dalam penelitian ini betujuan untuk mengetahui jumlah dan volume angkutan sedimen yang masuk ke intake. Estimasi yang dipilih adalah Formula Meyer Petter Muller karena mengacu kepada estimasi yang lebih tinggi. Maka jumlah angkutan sedimen adalah 33,385 ton/hari dan volume sedimen 12,62 m3/hari.

\section{METODOLOGI PENELITIAN}

\section{Lokasi Penelitian}

Lokasi penelitian ini dilakukan di Waduk Panglima Besar Jenderal Soedirman atau yang sering disebut Waduk Mrica yang berada di Kecamatan Bawang Kabupaten Banjarnegara atau tepatnya $10 \mathrm{~km}$ arah barat Kota Banjarnegara, dengan panjang sekitar 6,5 km dan luas genangan sekitar 1.250 ha sebagaimana pada Gambar 2.

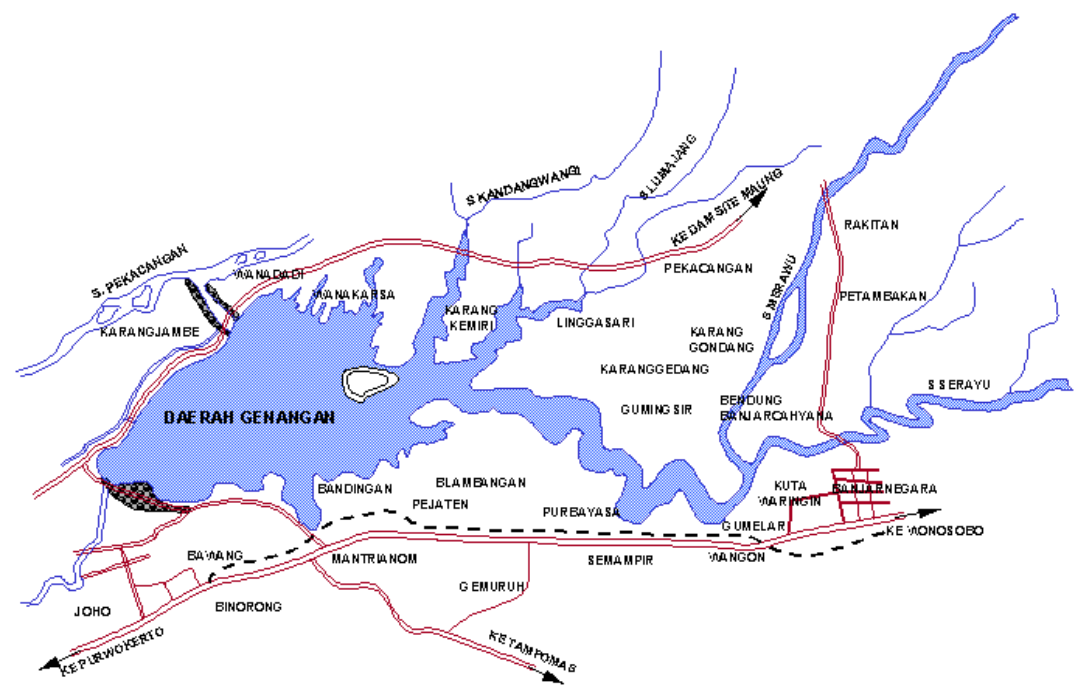

Gambar 2. Lay Out Waduk Mrica

Sumber : T. Marhendi, 2013)

\section{Data Penelitian}

Data yang diperlukan dalam penelitian ini berupa data debit aliran di waduk Mrica, luas penampang di waduk, konsentrasi sedimen dan diameter butiran sedimen. Debit aliran dalam penelitian ini menggunakan data tahun 2005-2014, serta data luas penampang waduk yang didapat dari PT. Uni Indonesia Power UBP Waduk Mrica. Data Konsentrasi sedimen diperoleh dari kajian PT. Indonesia Power 2017dan diameter butiran sedimen menggunakan data kesesuaian berdasarkan hasil penelitian sejenis di lokasi yang sama.

\section{Analisis dan Pembahasan}

Analisis dilakukan menggunakan model angkutan sedimen metode Mayer Petter Muller. Angkutan Sedimen Metode Mayer Petter Muller termasuk dalam persamaan yang diperoleh dengan pendekatan empirik. Persamaan ini dianggap lebih unggul dibandingkan dengan persamaan - persamaan yang lainnya karena range data yang digunakan sangat besar [6]. Untuk perhitungan angkutan sedimen ini ada 2 yaitu :

1. Suspended Load

Besarnya beban layang dihitung dengan menggunakan persamaan sebagai berikut [9]:

Qs $=0,0864 \times$ Cs $\times$ Qw

Nilai Cs atau konsentrasi sedimen di waduk Mrica diperoleh dari dinas PT. Indonesia Power (2017:1415), dengan penjelasan konsentrasi sedimen rata - rata pertahun di sungai Serayu Cs $=0,11 \mathrm{mg} / \mathrm{l}$, sungai Merawu Cs = 0,30 mg/l, dan sungai Lumajang Cs = 0,05 mg/l. Sehingga konsentrasi sedimen yang terjadi di waduk Mrica rata-rata adalah 0,153 mg/l.

2. Bed Load

Perhitungan ini menggunakan persamaan sebagai berikut :

$\gamma \mathrm{W} \frac{Q s}{Q}\left(\frac{K s}{K s}\right)^{\frac{3}{2}} h I=0,047(\gamma \mathrm{s}-\gamma \mathrm{w}) \mathrm{dm}+0,25\left(\frac{\gamma w}{g}\right)^{\frac{1}{2}}(Q b)^{\frac{2}{3}}$ 


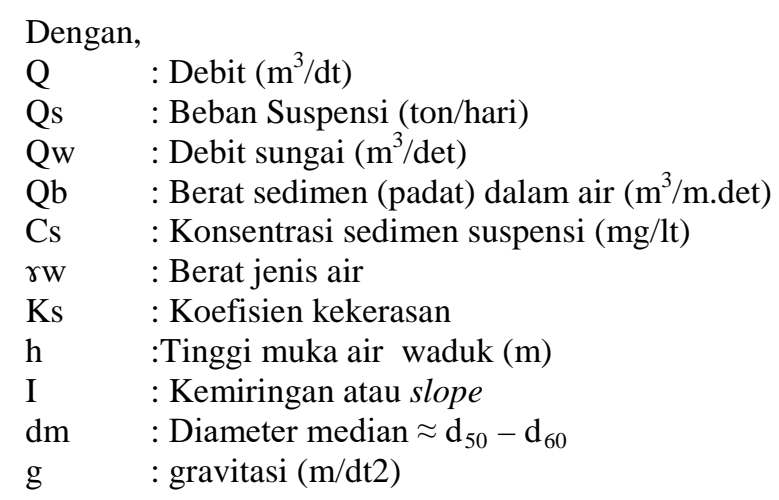

Diameter butiran sedimen $(\mathrm{dm})$ dan berat jenis sedimen $(\gamma \mathrm{s})$ diperoleh dengan mengacu Suroso (2007). Mengacu hasil penelitian tersebut, diameter-diameter butiran sedimen yang penting dan sering digunakan adalah $\mathrm{d}_{16}=0,005 \mathrm{~mm}, \mathrm{~d}_{25}=0,015 \mathrm{~mm}, \mathrm{~d}_{50}=0,03 \mathrm{~mm}, \mathrm{~d}_{90}=0,08 \mathrm{~mm}$, dan berat jenis $(\gamma \mathrm{s})=$ 2,65. Dengan demikian, diameter butiran sedimen median $\approx \mathrm{d}_{50}-\mathrm{d}_{60}=0,03 \mathrm{~mm}$.

\section{HASIL DAN PEMBAHASAN (10 PT)}

Analisis Angkutan Sedimen 2005-2014

Hasil analisis angkutan sedimen selama 10 tahun dari tahun 2005 sampai tahun 2014 dapat dilihat pada Tabel 1 berikut ini.

Tabel 1. Hasil perhitungan Suspended Load di Waduk Mrica Sumber : Analisis, 2018

\begin{tabular}{llll}
\hline Tahun & $\begin{array}{l}\text { Qs } \\
\text { (t/hari) }\end{array}$ & Qb (t/hari) & QS (t/hari) \\
\hline 2005 & 0,968 & 0,0000621 & 0,968321772 \\
2006 & 0,835 & 0,0000352 & 0,834711008 \\
2007 & 0,852 & 0,0000284 & 0,851860609 \\
2008 & 0,991 & 0,0000426 & 0,991052779 \\
2009 & 0,968 & 0,0000391 & 0,967977568 \\
2010 & 1,471 & 0,0001373 & 1,471347144 \\
2011 & 0,910 & 0,0000401 & 0,909527315 \\
2012 & 1,020 & 0,0000431 & 1,019530184 \\
2013 & 0,917 & 0,0000315 & 0,916561287 \\
2014 & 0,917 & 0,0000301 & 0,916694429 \\
\hline
\end{tabular}




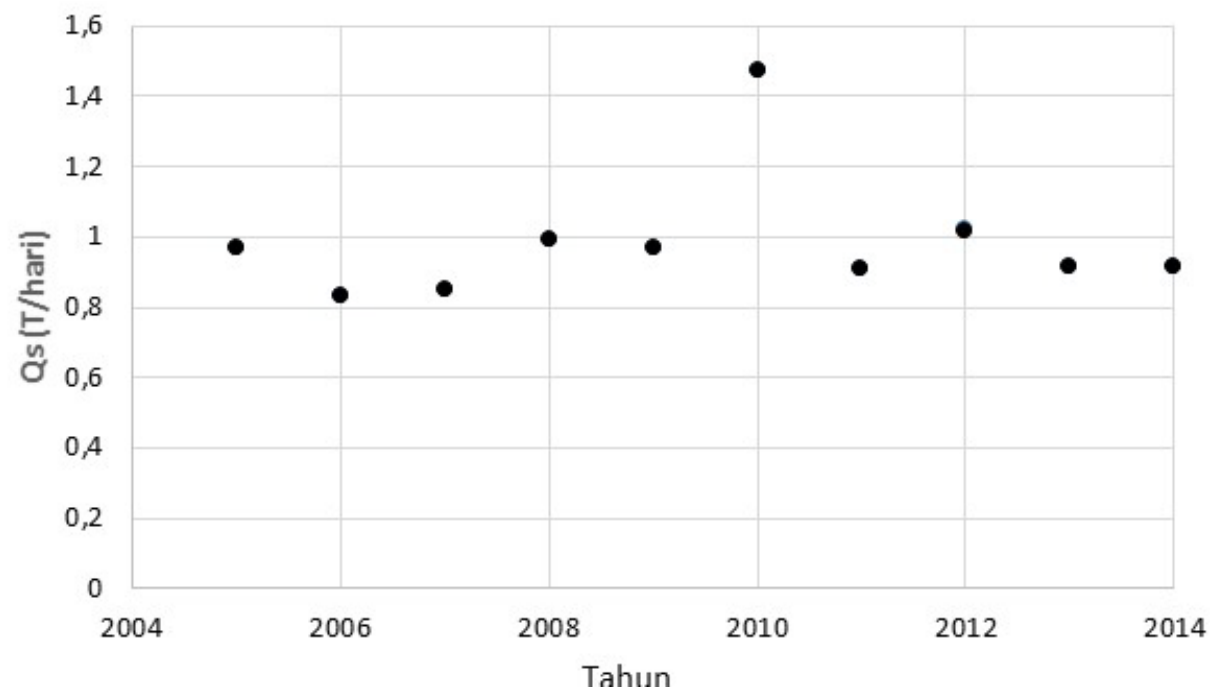

Gambar 3. Analisis peningkatan sedimen masuk waduk 2005-2014 berdasarkan metode Angkutan sedimen

Berdasarkan Gambar 3, debit sedimen yang masuk ke Waduk Mrica berfluktuatif. Pada tahun 2006 cenderung turun hingga 0,133 T/hari kemudian di tahun 2007 mengalami kenaikan sekitar 0,017 T/hari. Terjadi kenaikan cukup tinggi pada tahun 2010 dengan kenaikan sedimen sekitar 0,5 T/hari. Secara keseluruhan rerata kenaikan dan penurunan mencapai 0,005 T/hari. Fluktuatif perubahan debit sedimen ini salah satunya dipengaruhi oleh fluktuatif debit Sungai Serayu yang masuk ke Waduk.

\section{Analisis Debit Sedimen 10 Tahun Mendatang}

Analisis ini dimaksudkan untuk memprediksi perubahan atau peningkatan debit sedimen yang masuk Waduk Mrica selama 10 tahun mendatang sejak tahun 2014 sampai 2024. Analisis dilakukan menggunakan metode angkutan sedimen dan statistika.

Parameter statistik data debit sedimen yang perlu diperkirakan untuk pemilihan distribusi yang sesuai dengan sebaran data. Besarnya parameter ini, dapat diukur yakni melalui perhitungan parameter statistik untuk mencari $(\mathrm{Xi}-\mathrm{X}),(\mathrm{Xi}-\mathrm{X})^{2},(\mathrm{Xi}-\mathrm{X})^{3},(\mathrm{Xi}-\mathrm{X})^{4}$.

Dimana :

$X i \quad=$ besarnya curah hujan maksimum $(\mathrm{mm})$

$\bar{X} \quad=$ rata-rata curah hujan maksimum $(\mathrm{mm})$

Tabel 2. Parameter Statistik Data Debit Sedimen

\begin{tabular}{lllllll}
\hline No. & Tahun & \multicolumn{1}{c}{$\mathrm{X}$} & \multicolumn{1}{c}{$(\mathrm{Xi}-\bar{X})$} & \multicolumn{1}{c}{$(\mathrm{Xi}-\bar{X})^{2}$} & \multicolumn{1}{c}{$(\mathrm{Xi}-\bar{X})^{3}$} & $(\mathrm{Xi}-\bar{X})^{4}$ \\
\hline 1 & 2006 & 0,834711 & $-0,15005$ & 0,022514 & $1,14122 \times 10^{-5}$ & $1,69623 \times 10^{-20}$ \\
2 & 2007 & 0,851861 & $-0,1329$ & 0,017662 & $5,50943 \times 10^{-6}$ & $9,21355 \times 10^{-22}$ \\
3 & 2011 & 0,909527 & $-0,07523$ & 0,00566 & $1,81294 \times 10^{-7}$ & $1,08028 \times 10^{-27}$ \\
4 & 2013 & 0,916561 & $-0,0682$ & 0,004651 & $1,006 \times 10^{-7}$ & $1,0242 \times 10^{-28}$ \\
5 & 2014 & 0,916694 & $-0,06806$ & 0,004633 & $9,94269 \times 10^{-8}$ & $9,77274 \times 10^{-29}$ \\
6 & 2009 & 0,967978 & $-0,01678$ & 0,000282 & $2,23297 \times 10^{-11}$ & $2,48616 \times 10^{-43}$ \\
7 & 2005 & 0,968322 & $-0,01644$ & 0,00027 & $1,97187 \times 10^{-11}$ & $1,51186 \times 10^{-43}$ \\
8 & 2008 & 0,991053 & 0,006294 & $3,96 \times 10^{-5}$ & $6,21889 \times 10^{-14}$ & $1,49573 \times 10^{-53}$ \\
9 & 2012 & 1,01953 & 0,034772 & 0,001209 & $1,76751 \times 10^{-9}$ & $9,75988 \times 10^{-36}$ \\
10 & 2010 & 1,471347 & 0,486589 & 0,236769 & 0,013273098 & $3,10377 \times 10^{-8}$ \\
& $\sum$ & 9,847584096 & 0 & 0.29368837 & 0.013290403 & $3,10377 \times 10^{-8}$ \\
& $\bar{X}$ & 0,98475841 & & & & \\
\hline
\end{tabular}

Sumber : Analisis, 2018 
Berikut adalah hasil dari perhitungan prediksi debit 10 mendatang (2015-2024) sebagaimana dapat dilihat pada Tabel 3.

Tabel 3.Prediksi Peningkatan Debit Sedimen di Waduk Mrica 2015-2024

\begin{tabular}{cc}
\hline Tahun & $\begin{array}{c}\text { Debit Sedimen Total QS } \\
(\mathrm{t} / \text { hari })\end{array}$ \\
\hline 2015 & 0,9368 \\
2016 & 0,9568 \\
2017 & 1,025 \\
2018 & 1,0933 \\
2019 & 1,1615 \\
2020 & 1,1886 \\
2021 & 1,2157 \\
2022 & 1,2428 \\
2023 & 1,2699 \\
2024 & 1,297 \\
\hline
\end{tabular}

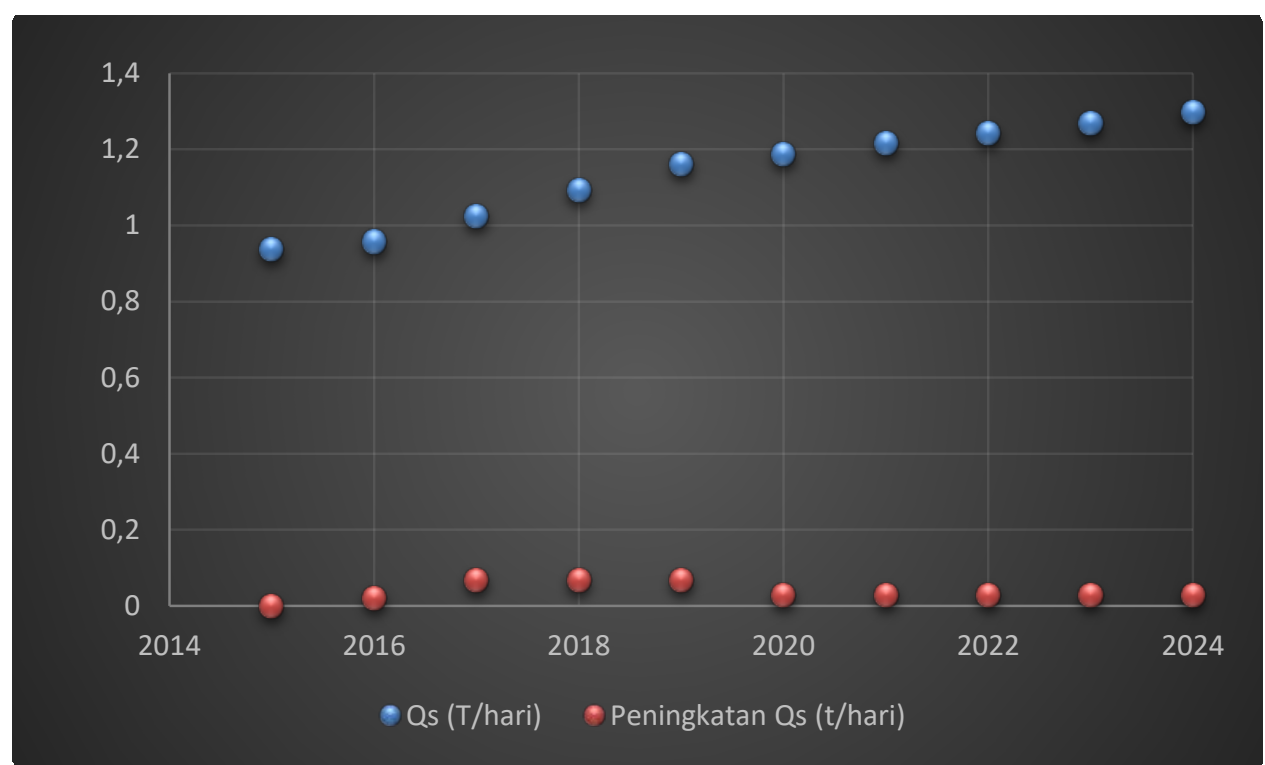

Gambar 4. Prediksi Peningkatan Debit Sedimen di Waduk Mrica 2015-2024 dan peningkatan pertahunnya Sumber : Analisis, 2018

Berdasarkan Gambar 4, di prediksi terjadi peningkatan debit sedimentasi yang masuk ke Waduk Mrica dengan rerata peningkatan 0,04 T/hari tiap tahun.atau rerata terjadi peningkatan debit sedimen sebesar $11,11 \%$ dari total peningkatan debit sedimen.

\section{KESIMPULAN}

Hasil Analisis debit sedimen mulai dari tahun 2005 - 2014 mengalami kenaikan dan penurunan yang dipengaruhi oleh debit aliran yang terjadi di Sungai Serayu di hulu Waduk Mrica. Dan prediksi sampai 10 tahun mendatang (2015-2024) debit sedimen mengalami peningkatan setiap tahunnya dengan rerata peningkatan $11,11 \%$. 
DAFTAR PUSTAKA (10 PT)

[1] T. Marhendi, "Penentuan Erosi Lahan Menggunakan Formula Usle Dengan Dasar Karakteristik Tanah", Jurnal Techno,vol 15, no. 2, pp 9-14, 2014.

[2] T. Marhendi, "Strategi Pengelolaan Sedimentasi Waduk (Management Strategy to Reservoir Sedimentation)", Jurnal Techno, vol 14, no. 2 : pp 29-41, 2013.

[3] T. Marhendi, "Pengaruh Faktor Panjang Kelerengan terhadap Penentuan Awal Erosi Lahan”, Jurnal Riset dan Teknologi, LPPM UMP, 2017

[4] Sunandar, Riska, “Analisis Erosi dan Sedimentasi Bendungan Mrica Banjarnegara”, Program Pasca Sarjana. Universitas Muhammadiyah Yogyakarta, Yogyakarta, 2017.

[5] T. Marhendi, "Hubungan Karakteristik Curah Hujan dan Perubahan Volume Sedimentasi Waduk (Studi Kasus Waduk Pangsar Soedirman)”, E-journal Undip, Oktober 2018.

[6] Kironoto, Bambang A, "Hiraudila Transpor Sedimen”, Program Pasca Sarjana. Universitas Gadjah Mada, Yogyakarta, 1997.

[7] Tri Asmoro, Anton, “Analisis Volume Sedimen Waduk Wonogiri di Muara Sungai Keduang”, Program Pasca Sajrana, Universitas Muhammadiyah Surakarta, Surakarta, 2015.

[8] Yogi, Pradhitya, “Analisis Angkutan Sedimen Dasar Sungai Progo dengan Metode Empiris (Meyer Peter \& Muller, Einstein Dan Frijink)”, Universitas Muhammadiyah Yogyakarta, Yogyakarta, 2017.

[9] Munandar, Aris, dkk, “Analisis Laju Angkutan Sedimen Bagi Perhitungan Kantong Lumpur pada D.I Perkotaan Kabupaten Batubara”. Teknik Sipil, Universitas Sumatera Utara, Vol 3 No. 4, 2014.

[10] Anonim, "PT. Indonesia Power Unit Pembangkit Mrica, Laporan Pelaksanaan Penyelidikan Sedimentasi Waduk PLTA PB. Sudirman”, Banjarnegara. 2010.

[11] Anonim, "PT. Indonesia Power Unit Pembangkit Mrica, Laporan Pelaksanaan Penyelidikan Sedimentasi Waduk PLTA PB. Sudirman”, Banjarnegara, 2015.

[12] Soewarno, "Hidrologi Aplikasi Metode Statistik Untuk Analisa Data”, Nova, Bandung, 1995.

[13] Suroso, "Optimasi Operasi Waduk Mrica untuk Memaksimumkan Produksi Energi Listrik Menggunakan KombinasiPemrograman Dinamik Stokastik dan Logika Fuzzy”, Laporan Tahunan Penelitian HIBAH PEKERTI, Unsoed Purwokerto, 2007. 
